\title{
Structural control with tuned inertial mass electromagnetic transducers
}

\author{
Takehiko Asai $^{1 *}$, Yoshikazu Araki ${ }^{2}$ and Kohju Ikago ${ }^{3}$ \\ ${ }^{1}$ Faculty of Engineering, Information and Systems, University of Tsukuba, Tsukuba, Ibaraki 305-8573, Japan \\ 2 Department of Architecture and Architectural Engineering, Kyoto University, Nishikyo, Kyoto 615-8540, Japan \\ ${ }^{3}$ International Research Institute of Disaster Science, Tohoku University, Sendai, Miyagi 980-0845, Japan
}

\section{SUMMARY}

This paper investigates the validity of the tuned inertial mass electromagnetic transducer (TIMET) applied to building structures subjected to seismic motions. The TIMET is a device inspired by two innovative structural control devices proposed recently, i.e., tuned viscous mass damper (TVMD) and electromagnetic transducer (ET). The TIMET consists of a spring, an inertial mass produced by a ball screw mechanism, and an ET part composed of a motor and an electrical circuit. The stiffness of the spring is tuned such that the inertial mass resonates with the vibrating building. This makes the motor installed in parallel with the inertial mass run up in an efficient way and the vibration energy is converted to electrical energy effectively. As a result, vibration of the building decays fast and electrical energy is stored. This generated energy is reusable for the self-powered control systems, structural health monitoring, emergency power source, and so on. In this paper, through numerical simulation studies employing the scaled three-story building model proposed for benchmark studies, the vibration reduction and energy harvesting capabilities of the TIMET is explored and the application potentiality to civil structures is discussed. Copyright (c) 2017 John Wiley \& Sons, Ltd.

Received ...

KEY WORDS: structural control; tuned inertial mass electromagnetic transducer; energy harvesting; earthquake engineering; numerical siumlation

\section{INTRODUCTION}

Structural control technologies play a critical role to protect our lives and properties from severe natural disasters such as earthquakes and strong winds. To date, various kinds of structural control devices for civil structures have been proposed by many researchers and engineers [1]. One of the structural control strategies which already reached the mature stage is the tuned mass damper (TMD) [2]. The TMD is a dynamic vibration absorber, consisting of an auxiliary mass located at the top of the building and connected through a spring and damper. And the spring stiffness is tuned to absorb the input energy from external disturbances effectively and to reduce the amplitude of the building vibration. However, for practical reasons, the auxiliary mass is limited to on the order of several percent of the mass of the total structure. Thus this makes the TMD less effective for strong disturbances such as earthquake loadings.

To solve the problem of the limited auxiliary mass, various kinds of the structural control devices for civil structures with the inerter have been developed by many researchers including the tuned viscous mass damper (TVMD) [3], tuned inerter damper (TID) [4, 5], tuned mass damper inerter (TMDI) [6], and T tuned inerter damper (TTID) [7]. The inerter was introduced in [8] originally.

\footnotetext{
${ }^{*}$ Correspondence to: Faculty of Engineering, Information and Systems, University of Tsukuba, Tsukuba, Ibaraki 3058573, Japan. E-mail: asai@kz.tsukuba.ac.jp 
The force produced by the inerter is proportional to the relative acceleration between both ends and the amplified equivalent mass effect, i.e., inertance, is realized by a mechanism using the hydraulic [9], ball screw [3], or rack and pinion inerter [8, 10].

For example, the TVMD proposed in [3] is divided into two parts: a rotational mass damper and a supporting spring. The rotational mass damper part consists of a ball screw mechanism, a rotating mass, and a damper made of a viscous material. The ball screw mechanism is employed to convert translational motion to rotational behavior. Then a rotary inertial mass effect is produced by rotating the relatively small physical mass and an amplified equivalent mass effect, i.e., inertance, is obtained. The system which can produce the amplified equivalent mass up to on the order of thousandfold have been developed [11]. This makes it possible for the TVMD to realize relatively large mass ratio to the structure, which typical TMDs can not realize. At the same time the input energy is absorbed by the viscous material as heat. In this system, the inertance and the viscous damper are connected in parallel and the spring is arranged in series with them. The device is connected to the structure through the spring, thus the stiffness of the spring is tuned so that the rotational inertial mass resonates with the structure, which leads to improvements of the energy absorption efficiency and vibration mitigation performance [12,13].

While as another structural control device, the electromagnetic transducer (ET) has been proposed in $[14,15]$. This device is composed of a ball screw mechanism and a motor, thus in the same way as the TVMD, linear motion is changed to rotation which spins the motor through the ball screw mechanism. Then mechanical energy is converted into electrical energy with the motor and vibration decay is induced. In this case, the motor works as a generator. In addition, the motor can be used as an actuator and the multiple ETs can share the generated power. Thus the multiple ETs enable a self-powered control system by re-injecting the control force through a system called a Regenerative Force Actuation (RFA) Network [14, 16].

The authors have focused on the energy absorption capability of the TVMD, in which the inertance and damping part are arranged in parallel unlike the other tuned inerter devices, and the energy conversion system of the ET. Also, the fact that the ball screw mechanism is employed in both devices in common has attracted the authors' attention. Then by a combination of these two devices, tuned inertial mass electromagnetic transducers (TIMETs), which can increase energy generation efficiency, can be realized by one ball screw mechanism and have been proposed in the authors' previously published work [17]. In that paper, the authors showed the effectiveness of the proposed device on a single-degree-of-freedom (SDOF) oscillator as an energy harvester through numerical simulation studies.

The purpose of this paper is to asses not only the vibration reduction capability but also the energy harvesting efficiency of the TIMET on a building subjected to seismic motions. Because the external power grid is extremely unreliable during seismic events, the generated power is of value for the purpose of self-powered control system, structural health monitoring, emergency power source and so forth. In this paper, first, the mechanism of the TIMET and an SDOF oscillator model with the TIMET are reviewed briefly. And we introduce an effective TIMET configuration combined with the TMD system for building structures [18], in addition to the configuration where the TIMET are installed between two adjacent floors the same way as the TVMD proposed in literature [12]. Then the equation of motions are derived and the parameter design methods are introduced. Subsequently numerical simulation studies are implemented using the scaled three-story building model subjected to a disturbance created by the Kanai-Tajimi filter and three earthquake records. Conclusions obtained from this study then follow.

\section{MODELS FOR TUNED INERTIAL MASS ELECTROMAGNETIC TRANSDUCERS}

In this section, the mechanism of the TIMET proposed in [17] is reviewed briefly. First, the model of the TIMETs is introduced, and the equation of motion when the TIMET is installed on an SDOF oscillator is derived. Finally, the energy harvesting objective is defined. 


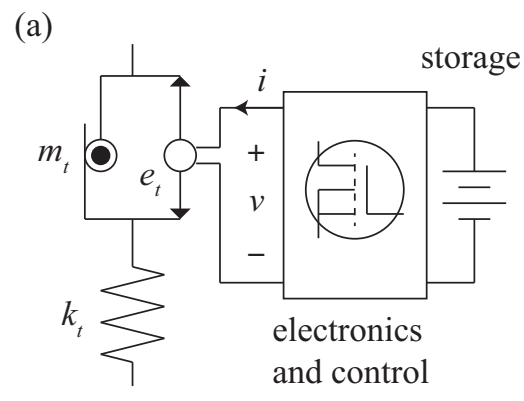

(b)

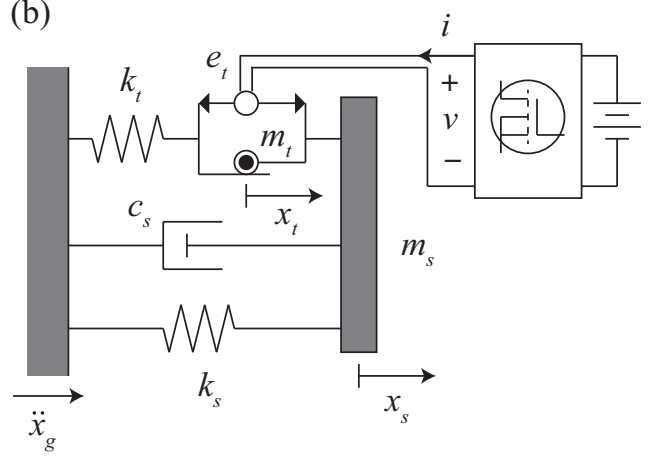

(c)

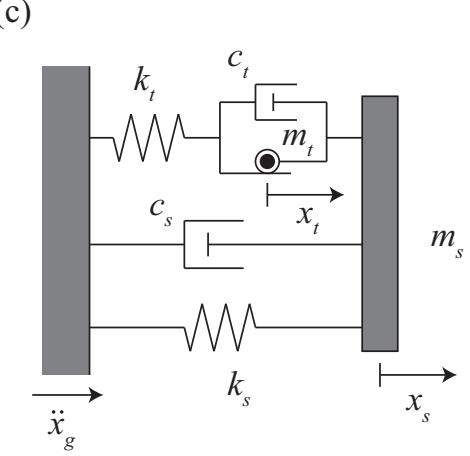

Figure 1. Schematic models: (a) TIMET, (b) SDOF oscillator with TIMET, and (c) Equivalent model of the SDOF oscillator with TIMET.

\subsection{Tuned inertial mass electromagnetic transducer}

The TIMET investigated in this research can be modeled as illustrated in Figure 1 (a). As can be seen, the TIMET consists of three parts: damping, inertial mass, and liner spring parts. To decay vibration induced by disturbance, ordinary dampers absorb vibration energy by converting into heat. While the TIMET provides damping by electromechanical coupling coefficient $e_{t}$ through a transducer and converts mechanical energy into electrical energy. The value of $e_{t}$ is defined by the magnetic field of the rotor and the lead of the ball screw mechanism. Then this generated energy can be stored for later use. In parallel with the motor, inertance $m_{t}$ is installed. As the inerter is realized through a ball screw mechanism, huge equivalent mass effect can be obtained by relatively small physical mass. And the linear spring whose stiffness is $k_{t}$ is installed in series with the damping and inertial mass. To improve energy absorbing efficiency and vibration mitigation performance, we need design the value of $k_{t}$ and control the current into the transducer $i$ appropriately.

\subsection{SDOF oscillator with TIMET}

The model of an SDOF oscillator with the TIMET is shown in Figure 1 (b) schematically. Let $m_{s}$, $c_{s}$, and $k_{s}$ be the mass, damping, and stiffness of the SDOF oscillator, then the equation of motion including the TIMET is derived as follows. If $x_{s}$ is the displacement relative to the ground of the SDOF oscillator and $x_{t}$ is the deformation of the inerter of the TIMET, the equation of motion of the oscillator would be

$$
m_{s} \ddot{x}_{s}+c_{s} \dot{x}_{s}+k_{s} x_{s}=-m_{s} \ddot{x}_{g}-f_{t}
$$

where $\ddot{x}_{g}$ is the ground acceleration and the force from the supporting spring whose stiffness is $k_{t}$ is given by

$$
f_{t}=k_{t}\left(x_{s}-x_{t}\right)
$$

while the equation of motion of the TIMET part becomes

$$
m_{t} \ddot{x}_{t}=e_{t} i+f_{t}
$$


1 Also the relationship between the current and voltage is defined as

$$
i=-Y v
$$

where $Y$ is a time-invariant feedback gain, which can be adjusted by a MOSFET. Under this feedback law, the electrical load can be considered a resistor. Thus $Y$ has units of admittance, so constant $Y$ is called static admittance in this paper. And the voltage $v$ can be expressed, from the back-EMF, as

$$
v=e_{t} \dot{x}_{t}
$$

Thus substituting Eq. (5) into Eq. (4) yields

$$
i=-Y e_{t} \dot{x}_{t}
$$

Hence Equation (3) can be rewritten, with respect to the velocity of the oscillator mass $\dot{x}_{t}$, as

$$
m_{t} \ddot{x}_{t}+c_{t} \dot{x}_{t}=f_{t}
$$

where

$$
c_{t}=Y e_{t}^{2}
$$

Thus the model for the SDOF oscillator with the TIMET shown in Figure 1 (b) can be remodeled by using a dashpot whose damping is $c_{t}$ as illustrated in Figure 1 (c). Therefore, by defining $\mathbf{x}=\left[\begin{array}{ll}x_{s} & x_{t}\end{array}\right]^{T}$, Equations (1) and (7) for the SDOF oscillator with the TIMET are expressed, in matrix form, as

$$
\mathbf{M} \ddot{\mathbf{x}}+\mathbf{C} \dot{\mathbf{x}}+\mathbf{K x}=-\mathbf{M} \Gamma \ddot{x}_{g}
$$

where

$$
\mathbf{M}=\left[\begin{array}{cc}
m_{s} & 0 \\
0 & m_{t}
\end{array}\right], \quad \mathbf{C}=\left[\begin{array}{cc}
c_{s} & 0 \\
0 & c_{t}
\end{array}\right], \quad \mathbf{K}=\left[\begin{array}{cc}
k_{s}+k_{t} & -k_{t} \\
-k_{t} & k_{t}
\end{array}\right], \quad \boldsymbol{\Gamma}=\left[\begin{array}{l}
1 \\
0
\end{array}\right]
$$

Note that hereafter in this paper, a dashpot is used to express the damping provided by TIMETs instead of an electromagnetic coupling coefficient and the electrical circuit.

\subsection{Energy harvesting objective}

To assess the energy harvesting potential for the proposed system, the power delivered to storage needs to be defined. As in [16, 19], the power delivered to storage is defined as the power extracted by the transducer minus the the transmission losses in the transducer and power electronic circuitry in this paper.

We have that the electromechanical transduction power $P_{e}(t)$ is preserved between mechanical and electrical sides of the transducers; i.e.,

$$
P_{e}(t)=i v=-c_{t} \dot{x}_{t}^{2}
$$

with the convention that positive $P_{e}(t)$ implies energy flow from the electrical network to the mechanical system. While typically the expression for the transmission losses $P_{d}(t)$ is quite complicated because the transmission losses happens due to various causes on the electronic hardware. However, for the purpose of this paper, we assume simply that the transmission loss is resistive; i.e.,

$$
P_{d}(t)=i^{2} R=\frac{c_{t}^{2} R}{e_{t}^{2}} \dot{x}_{t}^{2}
$$

where $R>0$ is the transmission resistance. For example, if the losses were entirely comprised of coil losses in the transducers, then $R$ is equal to the coil resistance. For more complex loss models, which incorporate MOSFET and diode conduction losses in the converters, past work has shown that these situations can also be conservatively approximated by a resistive loss term, together with a static power offset [20]. Defining $\bar{c}_{t}=e_{t}^{2} / R$, which is a positive value with units of viscous 
(a)

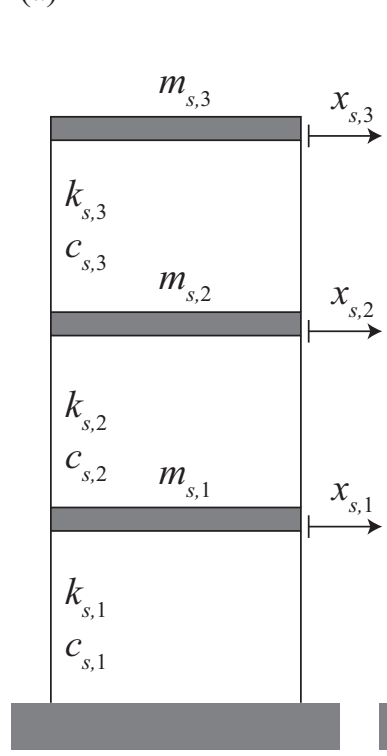

(b)

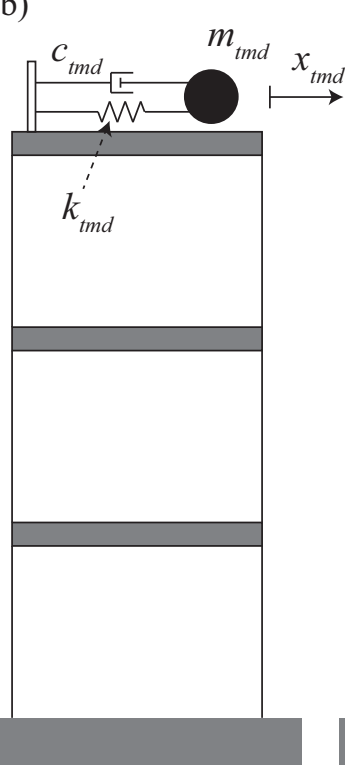

(c)

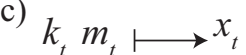

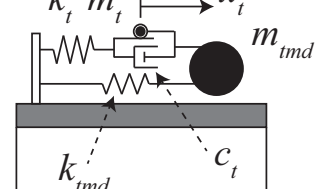

(d)

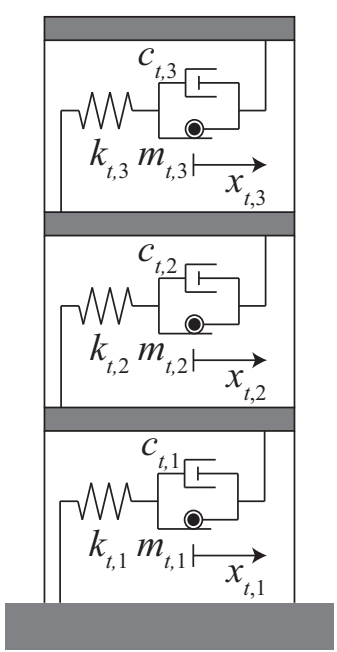

Figure 2. Building models: (a) Three-story building model, (b) TMD with ET, (c) TMD with TIMET, and (d) Interstory TIMET.

damping, gives

$$
P_{d}(t)=\frac{c_{t}^{2}}{\bar{c}_{t}} \dot{x}_{t}^{2}
$$

and physically, $\bar{c}_{t}$ represents the supplemental viscous damping that would relate the velocity $\dot{x}_{t}$ to the output force $c_{t} \dot{x}_{t}$ if the coil of the transducer is shorted. Thus $\bar{c}_{t}$ is determined by the specification of the transducer and represents the maximum viscous damping the transducer can exert.

With the above definitions and assumptions, we can now define the power delivered to storage as

$$
P_{g}(t)=-P_{e}(t)-P_{l}(t)=\left(c_{t}-\frac{c_{t}^{2}}{\bar{c}_{t}}\right) \dot{x}_{t}^{2}
$$

\section{PROBLEM FORMULATION}

To explore the possibilities of the TIMET on buildings subjected to seismic motions, a three-story shear building model illustrated in Figure 2 (a) is considered. For comparison, as shown in Figure 2 (b), a typical TMD employing an ET instead of viscous damper is investigated. In addition, two configurations of the TIMET for building structures are examined; one is a TMD with TIMET system, in which the TIMET mechanism is installed between the top floor and the auxiliary mass for the TMD as depicted in Figure 2 (c), and the other is an interstory TIMET system, in which the TIMETs are installed between floors as shown in Figure 2 (d). This is the typical configuration for the TVMD proposed in previous work [12]. In this section, the equations of motion of these systems are developed.

\subsection{Building model}

First of all, the equation of motion of the three-story shear building model shown in Figure 2 (a) is derived. Let $x_{s, j}, m_{s, j}, k_{s, j}, c_{s, j}$ be the translational displacement relative to the ground, mass, stiffness, and damping of the $j$ th floor. Then the equation of motion can be expressed by

$$
\mathbf{M}_{s} \ddot{\mathbf{x}}_{s}+\mathbf{C}_{s} \dot{\mathbf{x}}_{s}+\mathbf{K}_{s} \mathbf{x}_{s}=-\mathbf{M}_{s} \boldsymbol{\Gamma}_{s} \ddot{x}_{g}
$$


1 where $\ddot{x}_{g}$ is the ground acceleration, the displacement vector $\mathbf{x}_{s}$ is defined as $\mathbf{x}_{s}=$

$2\left[\begin{array}{lll}x_{s, 1} & x_{s, 2} & x_{s, 3}\end{array}\right]^{T}$, and the mass matrix $\mathbf{M}_{s}$, stiffness matrix $\mathbf{K}_{s}$, damping matrix $\mathbf{C}_{s}$, and 3 influence vector $\boldsymbol{\Gamma}_{s}$ become:

$$
\begin{gathered}
\mathbf{M}_{s}=\left[\begin{array}{ccc}
m_{1} & 0 & 0 \\
0 & m_{2} & 0 \\
0 & 0 & m_{3}
\end{array}\right], \quad \mathbf{K}_{s}=\left[\begin{array}{ccc}
k_{s, 1}+k_{s, 2} & -k_{s, 2} & 0 \\
-k_{s, 2} & k_{s, 2}+k_{s, 3} & -k_{s, 3} \\
0 & -k_{s, 3} & k_{s, 3}
\end{array}\right] \\
\mathbf{C}_{s}=\left[\begin{array}{ccc}
c_{s, 1}+c_{s, 2} & -c_{s, 2} & 0 \\
-c_{s, 2} & c_{s, 2}+c_{s, 3} & -c_{s, 3} \\
0 & -c_{s, 3} & c_{s, 3}
\end{array}\right], \quad \boldsymbol{\Gamma}_{s}=\left[\begin{array}{l}
1 \\
1 \\
1
\end{array}\right]
\end{gathered}
$$

4 respectively.

5 3.2. TMD with ET

6 Next, the equation of motion of the three-story building employing the TMD with ET system shown 7 in Figure 2 (b) is derived. Define the auxiliary mass, stiffness of the spring connecting the auxiliary 8 mass to the third floor, and damping induced by the ET as $m_{t m d}, k_{t m d}$, and $c_{t m d}$, respectively. 9 Then letting the relative displacement of the tuned mass be $x_{t m d}$ and the displacement vector be $10 \quad \mathbf{x}=\left[\begin{array}{ll}\mathbf{x}_{s}^{T} & x_{t m d}\end{array}\right]^{T}$ yields the equation of motion expressed as Equation (9) where the coefficient 11 matrices are:

$$
\begin{gathered}
\mathbf{M}=\left[\begin{array}{cc}
\mathbf{M}_{s} & \mathbf{0} \\
\mathbf{0} & m_{t m d}
\end{array}\right], \quad \mathbf{K}=\left[\begin{array}{cccc}
k_{s, 1}+k_{s, 2} & -k_{s, 2} & 0 & 0 \\
-k_{s, 2} & k_{s, 2}+k_{s, 3} & -k_{s, 3} & 0 \\
0 & -k_{s, 3} & k_{s, 3}+k_{t m d} & -k_{t m d} \\
0 & 0 & -k_{t m d} & k_{t m d}
\end{array}\right] \\
\mathbf{C}=\left[\begin{array}{cccc}
c_{s, 1}+c_{s, 2} & -c_{s, 2} & 0 & 0 \\
-c_{s, 2} & c_{s, 2}+c_{s, 3} & -c_{s, 3} & 0 \\
0 & -c_{s, 3} & c_{s, 3}+c_{t m d} & -c_{t m d} \\
0 & 0 & -c_{t m d} & c_{t m d}
\end{array}\right], \quad \boldsymbol{\Gamma}=\left[\begin{array}{c}
\boldsymbol{\Gamma}_{s} \\
1
\end{array}\right]
\end{gathered}
$$

\subsection{TMD with TIMET}

In a similar way, $\mathbf{M}, \mathbf{C}, \mathbf{K}$, and $\boldsymbol{\Gamma}$ matrices for the TMD with TIMET illustrated in Figure 2 (c) are developed. Define the equivalent mass, supporting spring stiffness, damping for the TIMET be $m_{t}, k_{t}$, and $c_{t}$, and let the deformation of the inerter be $x_{t}$ and the displacement vector be $\mathbf{x}=\left[\begin{array}{lll}\mathbf{x}_{s}^{T} & x_{t m d} & x_{t}\end{array}\right]^{T}$. Then by referring to the SDOF oscillator case given as Equation (10), the matrices for the equation of motion of form Equation (9) can be derived as follows:

$$
\begin{gathered}
\mathbf{M}=\left[\begin{array}{ccc}
\mathbf{M}_{s} & \mathbf{0} & \mathbf{0} \\
\mathbf{0} & m_{t m d} & 0 \\
\mathbf{0} & 0 & m_{t}
\end{array}\right], \\
\mathbf{K}=\left[\begin{array}{ccccc}
k_{s, 1}+k_{s, 2} & -k_{s, 2} & 0 & 0 & 0 \\
-k_{s, 2} & k_{s, 2}+k_{s, 3} & -k_{s, 3} & 0 & 0 \\
0 & -k_{s, 3} & k_{s, 3}+k_{t m d}+k_{t} & -k_{t m d}-k_{t} & k_{t} \\
0 & 0 & -k_{t m d}-k_{t} & k_{t m d}+k_{t} & -k_{t} \\
0 & 0 & k_{t} & -k_{t} & k_{t}
\end{array}\right], \\
\mathbf{C}=\left[\begin{array}{ccccc}
c_{s, 1}+c_{s, 2} & -c_{s, 2} & 0 & 0 & 0 \\
-c_{s, 2} & c_{s, 2}+c_{s, 3} & -c_{s, 3} & 0 & 0 \\
0 & -c_{s, 3} & c_{s, 3}+c_{t m d} & -c_{t m d} & 0 \\
0 & 0 & -c_{t m d} & c_{t m d} & 0 \\
0 & 0 & 0 & 0 & c_{t}
\end{array}\right], \quad \boldsymbol{\Gamma}=\left[\begin{array}{c}
\boldsymbol{\Gamma}_{s} \\
1 \\
0
\end{array}\right]
\end{gathered}
$$




\subsection{Interstory TIMET}

Finally, the equation of motion for the interstory TIMET configuration depicted in Figure 2 (d) 2 is developed. Assuming that the equivalent mass, supporting spring stiffness, and damping for the TIMET installed of the $j$ th floor are $m_{t, j}, k_{t, j}$, and $c_{t, j}$, respectively. In addition, let the deformation of the inerter of the $j$ th TIMET be $x_{t, j}$ and $\mathbf{x}_{t}=\left[\begin{array}{lll}x_{t, 1} & x_{t, 2} & x_{t, 3}\end{array}\right]^{T}$. Then defining $\mathbf{x}=\left[\begin{array}{ll}\mathbf{x}_{s}^{T} & \mathbf{x}_{t}^{T}\end{array}\right]^{T}$, the coefficient matrices for the equation given as Equation (9) are derived as: 3 4 5

$$
\begin{gathered}
\mathbf{M}=\left[\begin{array}{cc}
\mathbf{M}_{s} & \mathbf{0} \\
\mathbf{0} & \mathbf{M}_{t}
\end{array}\right], \quad \mathbf{M}_{t}=\left[\begin{array}{ccc}
m_{t, 1} & 0 & 0 \\
0 & m_{t, 2} & 0 \\
0 & 0 & m_{t, 3}
\end{array}\right], \\
\mathbf{K}=\left[\begin{array}{cccccc}
k_{s, 1}+k_{s, 2}+k_{t, 1}+k_{t, 2} & -k_{s, 2}-k_{t, 2} & 0 & -k_{t, 1} & k_{t, 2} & 0 \\
-k_{s, 2}-k_{t, 2} & k_{s, 2}+k_{s, 3}+k_{t, 2}+k_{t, 3} & -k_{s, 3}-k_{t, 3} & 0 & -k_{t, 2} & k_{t, 3} \\
0 & -k_{s, 3}-k_{t, 3} & k_{s, 3}+k_{t, 3} & 0 & 0 & -k_{t, 3} \\
-k_{t, 1} & 0 & 0 & k_{t, 1} & 0 & 0 \\
k_{t, 2} & -k_{t, 2} & 0 & 0 & k_{t, 2} & 0 \\
0 & k_{t, 3} & -k_{t, 3} & 0 & 0 & k_{t, 3}
\end{array}\right], \\
\mathbf{C}=\left[\begin{array}{cc}
\mathbf{C}_{s} & \mathbf{0} \\
\mathbf{0} & \mathbf{C}_{t}
\end{array}\right], \quad \mathbf{C}_{t}=\left[\begin{array}{ccc}
c_{t, 1} & 0 & 0 \\
0 & c_{t, 2} & 0 \\
0 & 0 & c_{t, 3}
\end{array}\right], \quad \mathbf{\Gamma}=\left[\begin{array}{c}
\boldsymbol{\Gamma}_{s} \\
\mathbf{0}
\end{array}\right]
\end{gathered}
$$

\section{PARAMETER DESIGN}

In this section, the parameter design methods for the systems developed in the previous section are explained.

\subsection{TMD with ET}

The TMD with ET can be considered as a typical TMD system except for the energy conversion manner. Thus the stiffness and damping for this system are determined, based on the method proposed for the TMD by Den Hartog [2], as

$$
\begin{gathered}
k_{t m d}=\left(\beta_{t m d} \omega_{r}\right)^{2} m_{t m d} \\
c_{t m d}=2 \zeta_{t m d} \beta_{t m d} \omega_{r} m_{t m d}
\end{gathered}
$$

where $\omega_{r}$ is the natural frequency of the $r$ th mode of the building and $\beta_{t m d}$ and $\zeta_{t m d}$ for the $r$ th $\quad 14$ mode are given by

$$
\beta_{t m d}=\frac{1}{1+\mu_{t m d}}, \quad \zeta_{t m d}=\sqrt{\frac{3 \mu_{t m d}}{8\left(1+\mu_{t m d}\right)}}
$$

And the mass ratio $\mu_{t m d}$ for the $r$ th mode is defined as

$$
\mu_{t m d}=\frac{\bar{M}_{t m d, r}}{\bar{M}_{s, r}}
$$

where $\bar{M}_{s, r}$ is the $r$ th modal mass of the building defined, with the $r$ th mode shape vector 17 $\mathbf{u}_{r}=\left[\begin{array}{lll}u_{r, 1} & u_{r, 2} & u_{r, 3}\end{array}\right]^{T}$, as

$$
\bar{M}_{s, r}=\sum_{j=1}^{3} m_{j} u_{r, j}^{2}
$$

and $\bar{M}_{t m d, r}$ is the $r$ th modal mass of the TMD placed on the 3rd floor and is given by

$$
\bar{M}_{t m d, r}=m_{t m d} u_{r, 3}^{2}
$$




\section{4.2. TMD with TIMET}

2 To determine the values for $k_{t}$ and $c_{t}$ for the TMD with TIMET system, these parameters are treated 3 as control gains for a stochastic optimal control problem subjected to a white noise input and the optimized values are sought through the algorithms presented in [21, 17].

By seeing the forces applied by the transducer and supporting spring of the TIMET as the control forces to the system, the equation of motion given by Equations (9) and (18) can be rewritten as

$$
\hat{\mathbf{M}} \ddot{\mathbf{x}}+\hat{\mathbf{C}} \dot{\mathbf{x}}+\hat{\mathbf{K}} \mathbf{x}=\hat{\mathbf{E}} f_{i}+\hat{\mathbf{F}} f_{s}-\hat{\mathbf{M}} \hat{\boldsymbol{\Gamma}} \ddot{x}_{g}
$$

7 where

$$
\begin{gathered}
\hat{\mathbf{M}}=\mathbf{M}, \quad \hat{\boldsymbol{\Gamma}}=\boldsymbol{\Gamma}, \quad \hat{\mathbf{K}}=\left[\begin{array}{ccccc}
k_{s, 1}+k_{s, 2} & -k_{s, 2} & 0 & 0 & 0 \\
-k_{s, 2} & k_{s, 2}+k_{s, 3} & -k_{s, 3} & 0 & 0 \\
0 & -k_{s, 3} & k_{s, 3}+k_{t m d} & -k_{t m d} & 0 \\
0 & 0 & -k_{t m d} & k_{t m d} & 0 \\
0 & 0 & 0 & 0 & 0
\end{array}\right] \\
\hat{\mathbf{C}}=\left[\begin{array}{ccccc}
c_{s, 1}+c_{s, 2} & -c_{s, 2} & 0 & 0 & 0 \\
-c_{s, 2} & c_{s, 2}+c_{s, 3} & -c_{s, 3} & 0 & 0 \\
0 & -c_{s, 3} & c_{s, 3}+c_{t m d} & -c_{t m d} & 0 \\
0 & 0 & -c_{t m d} & c_{t m d} & 0 \\
0 & 0 & 0 & 0 & 0
\end{array}\right], \hat{\mathbf{E}}=\left[\begin{array}{c}
0 \\
0 \\
0 \\
0 \\
1
\end{array}\right], \quad \hat{\mathbf{F}}=\left[\begin{array}{c}
0 \\
0 \\
1 \\
-1 \\
1
\end{array}\right]
\end{gathered}
$$

8 and $f_{i}$ and $f_{s}$ are the forces by the transducer and the spring defined by

$$
f_{i}=-c_{t} \dot{x}_{t}, \quad f_{s}=k_{t}\left(x_{t m d}-x_{s, 3}-x_{t}\right)
$$

respectively.

The equation of motion given as Equation (26) can be expressed as the state-space representation of the form

$$
\dot{\mathbf{z}}_{t}=\mathbf{A}_{t} \mathbf{z}_{t}+\mathbf{B}_{t i} f_{i}+\mathbf{B}_{t s} f_{s}+\mathbf{G}_{t} \ddot{x}_{g}
$$

where the state vector is $\mathbf{z}_{t}=\left[\begin{array}{ll}\mathbf{x}^{T} & \dot{\mathbf{x}}^{T}\end{array}\right]^{T}$ and $\mathbf{A}_{t}, \mathbf{B}_{t i}, \mathbf{B}_{t s}$, and $\mathbf{G}_{t}$ matrices are:

$$
\mathbf{A}_{t}=\left[\begin{array}{cc}
\mathbf{0} & \mathbf{I} \\
-\hat{\mathbf{M}}^{-1} \hat{\mathbf{K}} & -\hat{\mathbf{M}}^{-1} \hat{\mathbf{C}}
\end{array}\right], \quad \mathbf{B}_{t i}=\left[\begin{array}{c}
\mathbf{0} \\
-\hat{\mathbf{M}}^{-1} \hat{\mathbf{E}}
\end{array}\right], \quad \mathbf{B}_{t s}=\left[\begin{array}{c}
\mathbf{0} \\
-\hat{\mathbf{M}}^{-1} \hat{\mathbf{F}}
\end{array}\right], \quad \mathbf{G}_{t}=\left[\begin{array}{c}
\mathbf{0} \\
-\hat{\mathbf{\Gamma}}
\end{array}\right]
$$

Next, to apply the stochastic optimal control theory, the earthquake acceleration $\ddot{x}_{g}$ is modeled using a second-order noise filter called Kanai-Tajimi earthquake model [22] developed as

$$
\dot{\mathbf{z}}_{g}=\mathbf{A}_{g} \mathbf{z}_{g}+\mathbf{B}_{g} w
$$

$$
\ddot{x}_{g}=\mathbf{C}_{g} \mathbf{z}_{g}
$$

where

$$
\mathbf{A}_{g}=\left[\begin{array}{cc}
0 & 1 \\
-\omega_{g}^{2} & -2 \zeta_{g} \omega_{g}
\end{array}\right], \quad \mathbf{B}_{g}=\left[\begin{array}{l}
0 \\
1
\end{array}\right], \quad \mathbf{C}_{g}=\left[\begin{array}{ll}
\omega_{g}^{2} & 2 \zeta_{g} \omega_{g}
\end{array}\right]
$$

and the exogenous input $\omega$ is assumed to be white noise with spectral intensity $\Phi_{\omega}=1$.

Then defining $\mathbf{z}=\left[\begin{array}{ll}\mathbf{z}_{t}^{T} & \mathbf{z}_{g}^{T}\end{array}\right]^{T}$ leads to the augmented system given as

$$
\dot{\mathbf{z}}=\mathbf{A} \mathbf{z}+\mathbf{B}_{i} f_{i}+\mathbf{B}_{s} f_{s}+\mathbf{G} w
$$

where

$$
\mathbf{A}=\left[\begin{array}{cc}
\mathbf{A}_{t} & \mathbf{G}_{t} \mathbf{C}_{g} \\
\mathbf{0} & \mathbf{A}_{g}
\end{array}\right], \quad \mathbf{B}_{i}=\left[\begin{array}{c}
\mathbf{B}_{t i} \\
\mathbf{0}
\end{array}\right], \quad \mathbf{B}_{s}=\left[\begin{array}{c}
\mathbf{B}_{t s} \\
\mathbf{0}
\end{array}\right], \quad \mathbf{G}=\left[\begin{array}{c}
\mathbf{0} \\
\mathbf{B}_{g}
\end{array}\right]
$$

and the control forces given by Equation (28) are expressed, with the state $\mathbf{z}$, as

$$
f_{i}=-c_{t} \mathbf{C}_{i} \mathbf{z}, \quad f_{s}=k_{t} \mathbf{C}_{s} \mathbf{z}
$$


Then the closed form of the augmented state-space representation given by Equation (34) is derived as

$$
\dot{\mathbf{z}}=\left(\mathbf{A}-\mathbf{B}_{i} c_{t} \mathbf{C}_{i}+\mathbf{B}_{s} k_{t} \mathbf{C}_{s}\right) \mathbf{z}+\mathbf{G} w
$$

In this paper, to seek the optimal values for $k_{t}$ and $c_{t}$, two objective functions are defined; one is 3 the expectation of the square of the 3rd floor displacement $\mathcal{E} x_{s, 3}^{2}$ and the other is the expectation of the generated power $\mathcal{E} P_{g}$. Since the 3 rd floor distance is expressed as

$$
x_{s, 3}=\mathbf{C}_{d} \mathbf{z}
$$

with appropriate $\mathbf{C}_{d}$, thus the expectation of the square would be

$$
\mathcal{E} x_{s, 3}^{2}=\mathcal{E}\left(\mathbf{z}^{T} \mathbf{C}_{d}^{T} \mathbf{C}_{d} \mathbf{z}\right)=\mathbf{G}^{T} \mathbf{S}_{d} \mathbf{G}
$$

where $\mathbf{S}_{d}=\mathbf{S}_{d}^{T}>0$ is the solution to the Lyapunov equation [23]

$$
\left(\mathbf{A}-\mathbf{B}_{i} c_{t} \mathbf{C}_{i}+\mathbf{B}_{s} k_{t} \mathbf{C}_{s}\right)^{T} \mathbf{S}_{d}+\mathbf{S}_{d}\left(\mathbf{A}-\mathbf{B}_{i} c_{t} \mathbf{C}_{i}+\mathbf{B}_{s} k_{t} \mathbf{C}_{s}\right)+\mathbf{C}_{d} \mathbf{C}_{d}^{T}=\mathbf{0}
$$

Also, the velocity of the TIMET can be expressed as

$$
\dot{x}_{t}=\mathbf{C}_{i} \mathbf{z}
$$

thus from Equation (14), the expected power generation would be

$$
\mathcal{E} P_{g}=\mathcal{E}\left(\mathbf{C}_{i}^{T}\left(c_{t}-\frac{c_{t}^{2}}{\bar{c}_{t}}\right) \mathbf{C}_{i}^{T}\right)=\mathbf{G}^{T} \mathbf{S}_{p} \mathbf{G}
$$

where $\mathbf{S}_{p}=\mathbf{S}_{p}^{T}>0$ is the solution to the Lyapunov equation

$$
\left(\mathbf{A}-\mathbf{B}_{i} c_{t} \mathbf{C}_{i}+\mathbf{B}_{f} k_{t} \mathbf{C}_{s}\right)^{T} \mathbf{S}_{p}+\mathbf{S}_{p}\left(\mathbf{A}-\mathbf{B}_{i} c_{t} \mathbf{C}_{i}+\mathbf{B}_{f} k_{t} \mathbf{C}_{s}\right)+\mathbf{C}_{i}^{T}\left(c_{t}-\frac{c_{t}^{2}}{\bar{c}_{t}}\right) \mathbf{C}_{i}^{T}=\mathbf{0}
$$

Therefore these parameter design problems are reduced to optimization problems to seek for the values for $k_{t}$ and $c_{t}$ to minimize Equation (39) subject to Equation (40) and to maximize Equation (42) subject to Equation (43). These values can be obtained employing convex over-bounding techniques, as originally proposed by [24,25]. We will not delve into the details of these techniques here, but instead refer to [26], which outline the method in detail.

\subsection{Interstory TIMET}

In this paper, the parameters for the interstory TIMET system are designed by the method proposed for the TVMD in [12]. For these systems, the mass ratio for the $r$ th mode is defined as

$$
\mu_{i t}=\frac{\bar{M}_{t, r}}{\bar{M}_{s, r}}
$$

where the $r$ th modal mass is defined by the same way as Equation (24) and the $r$ th modal mass of the interstory TIMET is defined, with the $r$ th mode shape vector $\mathbf{u}_{r}$ as

$$
\bar{M}_{t, r}=m_{t, 1} u_{r, 1}^{2}+\sum_{j=2}^{3} m_{t, j}\left(u_{r, j}-u_{r, j-1}\right)^{2}
$$

because the TIMETs are installed between adjacent floors. Then we assume that the modal 21 equivalent masses $m_{t, 1}, m_{t, 2}$, and $m_{t, 3}$ are distributed in proportion to the stiffness of the building model, i.e., $k_{s, 1}, k_{s, 2}$, and $k_{s, 3}$, then the equivalent mass of the TIMETs are obtained, with a constant value

$$
c_{m}=\mu_{i t} \frac{\sum_{j=1}^{3} m u_{r, j}^{2}}{u_{r, 1}^{2}+\sum_{j=2}^{3} k_{i}\left(u_{r, j}-u_{r, j-1}\right)^{2} / k_{1}}
$$


Table I. Parameters for the small-scale three-story benchmark building model

\begin{tabular}{c|c||c|c||c|c}
\multicolumn{2}{c||}{ Mass $(\mathrm{kg})$} & \multicolumn{2}{l||}{ Stiffness $(\mathrm{kN} / \mathrm{m})$} & \multicolumn{2}{c}{ Damping (Ns/m) } \\
\hline$m_{1}$ & 98.3 & $k_{1}$ & 516 & $c_{1}$ & 125 \\
$m_{2}$ & 98.3 & $k_{2}$ & 684 & $c_{2}$ & 50 \\
$m_{3}$ & 98.3 & $k_{3}$ & 684 & $c_{3}$ & 50
\end{tabular}

as

$$
m_{t, j}=\frac{k_{j}}{k_{1}} c_{m} \quad \text { or } \quad m_{t, j}=\frac{\mu_{t}}{\omega_{r}^{2}} k_{s, j}
$$

2 Also, the stiffness and equivalent damping for the $j$ th TIMET are given by

$$
\begin{aligned}
k_{t, j} & =\left(\beta_{t} \omega_{r}\right)^{2} m_{t, j} \\
c_{t, j} & =2 \zeta_{t} \beta_{t} \omega_{r} m_{t, j}
\end{aligned}
$$

where $\beta_{t}$ and $\zeta_{t}$ for the system tuned to the $r$ th mode are defined as

$$
\beta_{t}=\frac{1-\sqrt{1-4 \mu_{i t}}}{2 \mu_{i t}}, \quad \zeta_{t}=\frac{\sqrt{3\left(1-\sqrt{1-4 \mu_{i t}}\right)}}{4}
$$

5 The details for this design method can be found in [12].

\section{NUMERICAL SIMULATION}

6 To evaluate the effectiveness of the TIMET on a building structure subjected to earthquake loadings 7 in terms of vibration mitigation and energy harvesting capability, numerical simulation studies 8 are carried out in this section. The model used in this paper is the scaled lightly damped three9 story building, which was previously investigated for various structural control strategies by many 
Table II. Parameters for the TMD with ET configuration

\begin{tabular}{c|ccccc} 
& I & II & III & IV & V \\
\hline$\mu_{t m d}$ & 0.02 & 0.03 & 0.04 & 0.05 & 0.1 \\
$m_{t m d}(\mathrm{~kg})$ & 3.87 & 5.80 & 7.74 & 9.67 & 19.34 \\
$k_{t m d}(\mathrm{kN} / \mathrm{m})$ & 4.34 & 6.39 & 8.36 & 10.25 & 18.67 \\
$c_{t m d}(\mathrm{Ns} / \mathrm{m})$ & 22.23 & 40.25 & 61.07 & 84.13 & 221.92 \\
$\bar{c}_{t m d}(\mathrm{Ns} / \mathrm{m})$ & 1160 & 1160 & 1160 & 1160 & 1160
\end{tabular}

Table III. Parameters for the TMD with TIMET configuration

\begin{tabular}{c|cccccccc} 
& I-D & I-P & II-D & II-P & III-D & III-P & IV-D & IV-P \\
\hline$m_{t m d}(\mathrm{~kg})$ & 7.74 & 7.74 & 7.74 & 7.74 & 7.74 & 7.74 & 7.74 & 7.74 \\
$k_{t m d}(\mathrm{kN} / \mathrm{m})$ & 8.36 & 8.36 & 8.36 & 8.36 & 8.36 & 8.36 & 8.36 & 8.36 \\
$\mu_{t t}$ & 0.02 & 0.02 & 0.05 & 0.05 & 0.1 & 0.1 & 0.15 & 0.15 \\
$m_{t}(\mathrm{~kg})$ & 0.15 & 0.15 & 0.39 & 0.39 & 0.77 & 0.77 & 1.16 & 1.16 \\
$k_{t}(\mathrm{kN} / \mathrm{m})$ & 1.10 & 5.46 & 0.47 & 0.47 & 1.07 & 0.97 & 1.92 & 1.42 \\
$c_{t}(\mathrm{Ns} / \mathrm{m})$ & 49.75 & 32.20 & 3.27 & 3.23 & 13.56 & 10.43 & 30.56 & 18.47 \\
$\bar{c}_{t}(\mathrm{Ns} / \mathrm{m})$ & 1160 & 1160 & 1160 & 1160 & 1160 & 1160 & 1160 & 1160
\end{tabular}

Table IV. Parameters for the interstory TIMET configuration

\begin{tabular}{c|cc} 
& $\mathrm{I}$ & $\mathrm{II}$ \\
\hline$\mu_{i t}$ & 0.1 & 0.15 \\
$m_{t, 1}$ & $44.17 \mathrm{~kg}$ & $66.25 \mathrm{~kg}$ \\
$m_{t, 2}, m_{t, 3}$ & $58.55 \mathrm{~kg}$ & $87.82 \mathrm{~kg}$ \\
$k_{t, 1}$ & $65.54 \mathrm{kNs} / \mathrm{m}$ & $116.18 \mathrm{kNs} / \mathrm{m}$ \\
$k_{t, 2}, k_{t, 3}$ & $86.88 \mathrm{kNs} / \mathrm{m}$ & $154.00 \mathrm{kNs} / \mathrm{m}$ \\
$c_{t, 1}$ & $699.5 \mathrm{Ns} / \mathrm{m}$ & $1456.6 \mathrm{Ns} / \mathrm{m}$ \\
$c_{t, 2}, c_{t, 3}$ & $927.3 \mathrm{Ns} / \mathrm{m}$ & $1930.8 \mathrm{Ns} / \mathrm{m}$ \\
$\bar{c}_{t, 1}, \bar{c}_{t, 2}, \bar{c}_{t, 3}$ & $236 \mathrm{kNs} / \mathrm{m}$ & $236 \mathrm{kNs} / \mathrm{m}$
\end{tabular}

As mentioned in the previous section, the parameters for the interstory TIMET are determined based on the method proposed for the TVMD in [12]. The mass ratio is assumed to be 0.1(case I) and 0.15 (case II) because due to the rotary inertial mass effect, a relatively high values can be applicable for the mass ratio for the interstory TIMET without installing huge actual masses. For this system, the TIMET are tuned to the 1st mode as well as the TIMET with ET cases. The calculated values are summarized in Table IV. The values for $\bar{c}_{t, 1}, \bar{c}_{t, 2}, \bar{c}_{t, 3}$ are referred to the model used in [29] as well.

\subsection{Kanai-Tajimi filter}

Now we investigate the responses to a stationary random process with a spectral density defined by the Kanai-Tajimi filter expressed by the state-space representation defined as Equations (31) and (32). The input excitation is the same as one used for designing the TMD with TIMET system, i.e., $\omega_{g}=15.4 \times 5=77 \mathrm{rad} / \mathrm{s}$ and $\zeta_{g}=0.64$ except for the spectral intensity. For the input excitation, the spectral intensity is adjusted such that the RMS values of the input acceleration takes a constant value of $\sigma_{\ddot{x}_{g}}=0.12 g$ with the gravitational acceleration $g$ as used in [32], i.e.,

$$
\mathbf{C}_{g}=\sqrt{2 S_{0} \pi}\left[\begin{array}{ll}
\omega_{g}^{2} & 2 \zeta_{g} \omega_{g}
\end{array}\right]
$$


where

$$
S_{0}=\frac{0.03 \zeta_{g}}{\pi \omega_{g}\left(4 \zeta_{g}^{2}+1\right)} g^{2}
$$

instead of $\mathbf{C}_{g}$ in Equation (33).

Table $\mathrm{V}$ provides the RMS values denoted by $\sigma$ of the relative displacement and absolute acceleration of each floor and the expected power generation defined by Equation (14). Notice that the power generation for the interstory TIMET cases is the summation of power generated from the three transducers. The observations obtained are summarized as follows:

1. As the auxiliary mass of the TMD with ET systems increases, the vibration mitigation performance is improving. While, for the TIMET with ET system, the case II shows the best power generation efficiency. This is due to the discrepancies of the input energies from the external disturbance.

2. By comparing the case III of the TMD with ET and the TMD with TIMET systems, it is shown that the use of TIMET with an appropriate equivalent mass instead of ET can reduce the response displacements by almost $6 \%$ and improve the power generation by around 5\% of the TMD systems without increasing the auxiliary mass. In particular, the case IV of the TMD with ET needs additional $1.94 \mathrm{~kg}$ mass to the case III, however, the same or better performances can be achieved in displacement reduction and power generation by the cases of II-D, II-P, III-D, III-P of the TMD with TIMET systems with only $0.39 \mathrm{~kg}$ and $0.77 \mathrm{~kg}$ additional equivalent mass effect. What is more is these additional equivalent mass effect can be realized with a much lighter physical mass due to the ball screw mechanism. When the mass ratios are increased to $\mu_{t t}=0.15$, the vibration of the auxiliary mass of the TMD is reduced, though the vibration reduction performances of the building are deteriorated.

3. The results obtained from the case V of the TMD with ET and the case I of the interstory TIMET show that the latter system has advantages on vibration reduction, power generation, and required actual mass under the same mass ratio condition $\mu_{t m d}=\mu_{i t}=0.1$. These results also show the superiority of the TIMET. Moreover, the case II of the interstory TIMET shows better performances than the case I in both vibration reduction and power generation.

\subsection{Earthquake records}

For further investigation of the effectiveness of the TIMET, we input three earthquake records including the 1995 JMA-Kobe, 1940 El Centro, and 1952 Taft records. To satisfy the scaling law based on the similitude law for the small-scale building model, the earthquakes are reproduced at 5 times the recorded rate. The time histories of the employed earthquake records are shown in Figure 3.

In addition to the peak (denoted by $p$ ) and RMS (denoted by $\sigma$ ) values of relative displacement and absolute acceleration of each floor and the auxiliary mass on the top, the generated energy during the duration of time 0 to $t_{f}$ defined as

$$
E_{g}=\int_{0}^{t_{f}} P_{g}(t) d t
$$

36

and the input energy from 0 to $t_{f}$ defined as [33]

$$
E_{i n}=-\int_{0}^{t_{f}}\left(\sum_{j=1}^{3} m_{j} \ddot{x}_{g} \dot{x}_{s, j}+m_{t} \ddot{x}_{g} \dot{x}_{t}\right) d t
$$

37 for the TMD with ET and TMD with TIMET systems and

$$
E_{\text {in }}=-\int_{0}^{t_{f}} \sum_{j=1}^{3} m_{j} \ddot{x}_{g} \dot{x}_{s, j} d t
$$




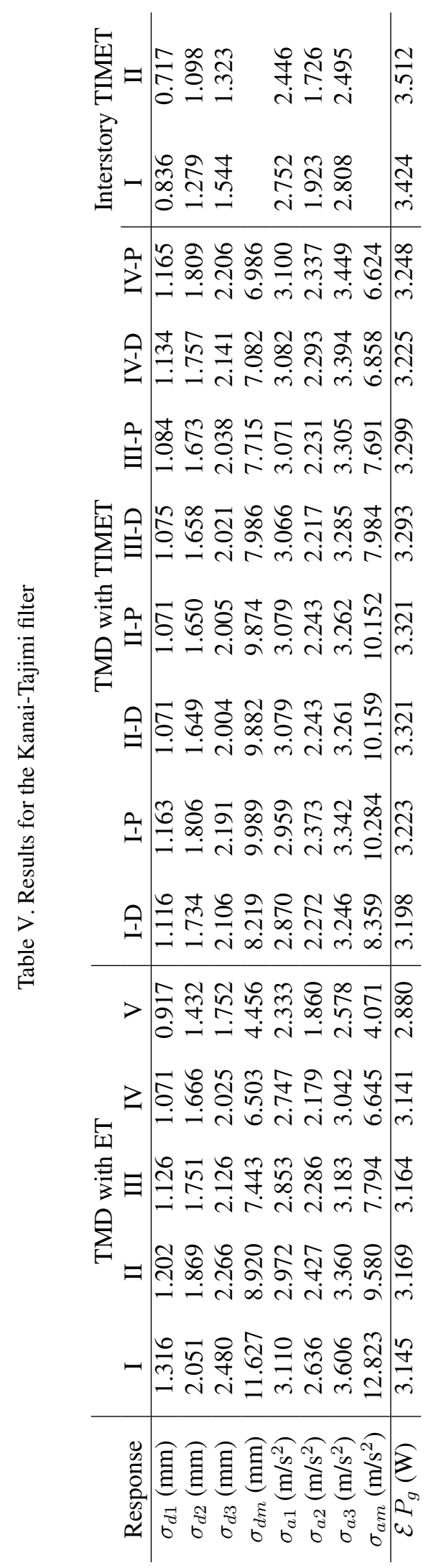


(a)

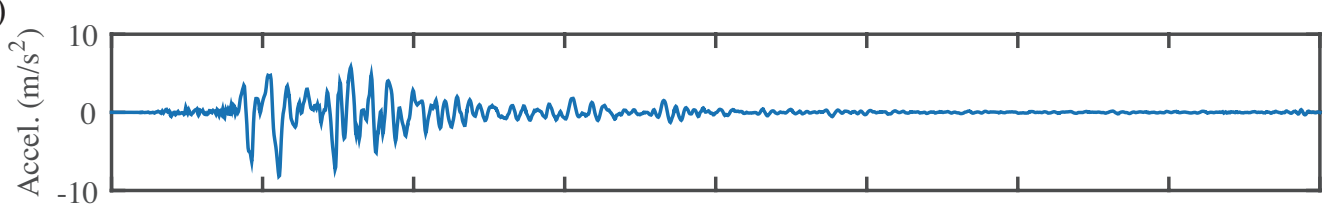

(b)

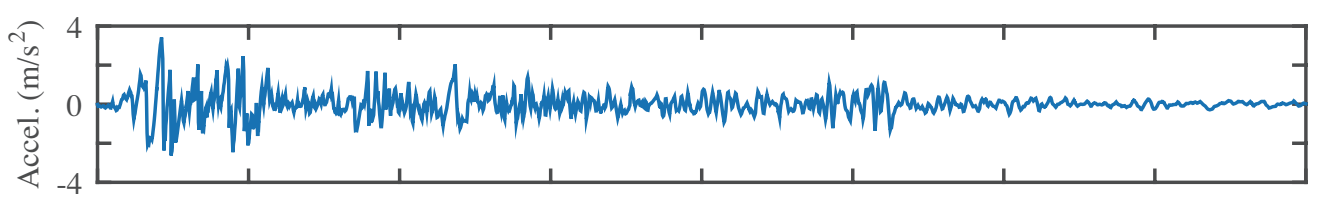

(c)

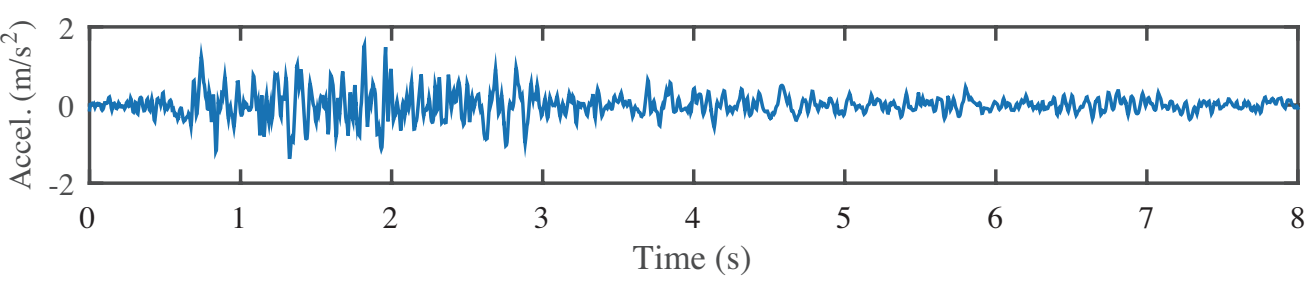

Figure 3. Input ground accelerations: (a) JMA Kobe, (b) El Centro, and (c) Taft.

for the interstory TIMET system, and we define the energy conversion ratio as $E_{g} / E_{i n}$. The time histories of the 3rd floor displacements, generated powers, and input energies for the case III of the TMD with ET, the case III-D of the TMD with TIMET, and the case I of the interstory TIMET are plotted in Figures 4, 5, and 6, respectively. Also, the values obtained from the numerical simulations 5 for all cases including the conversion ratios are summarized in Tables VI, VII, and VIII. The findings 6 made from these simulations are:

1. Overall we can find similar trends as the Kanai-Tajimi spectrum cases about the vibration mitigation and energy harvesting capability.

2. Unlike the Kanai-Tajimi spectrum, the TMD with TIMET systems show response acceleration performances better than or comparable to the case III of the TMD with ET system to the earthquake records, especially in the RMS values. This is because the TIMET systems work well for the free vibration after the forced vibration.

3. Although the generated energies are affected by the input energies, the systems employing the TIMETs show more effective energy conversion ratios than the TMD with ET systems for the three input earthquake records. 
(a)

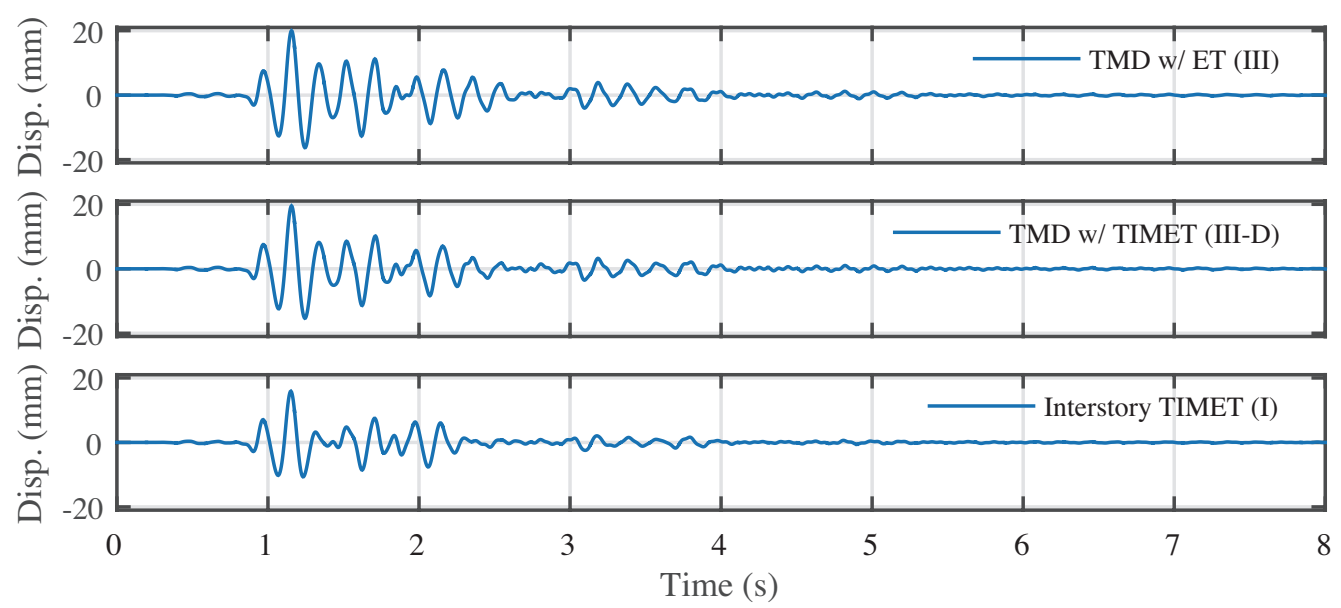

(b)

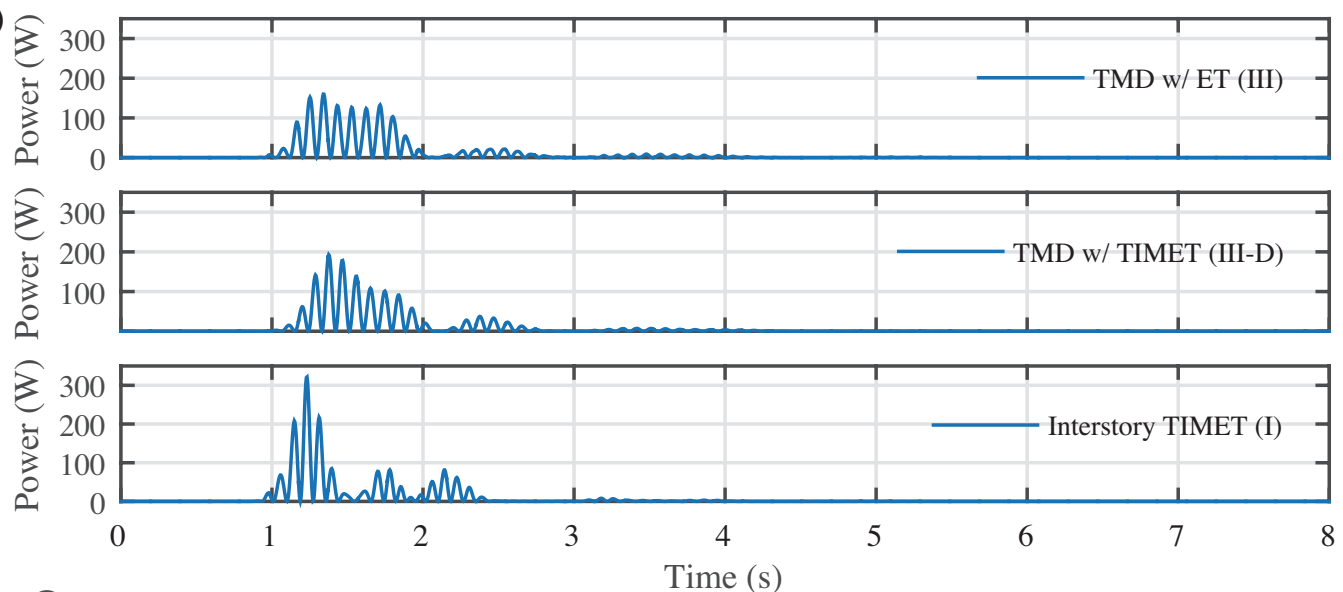

(c)

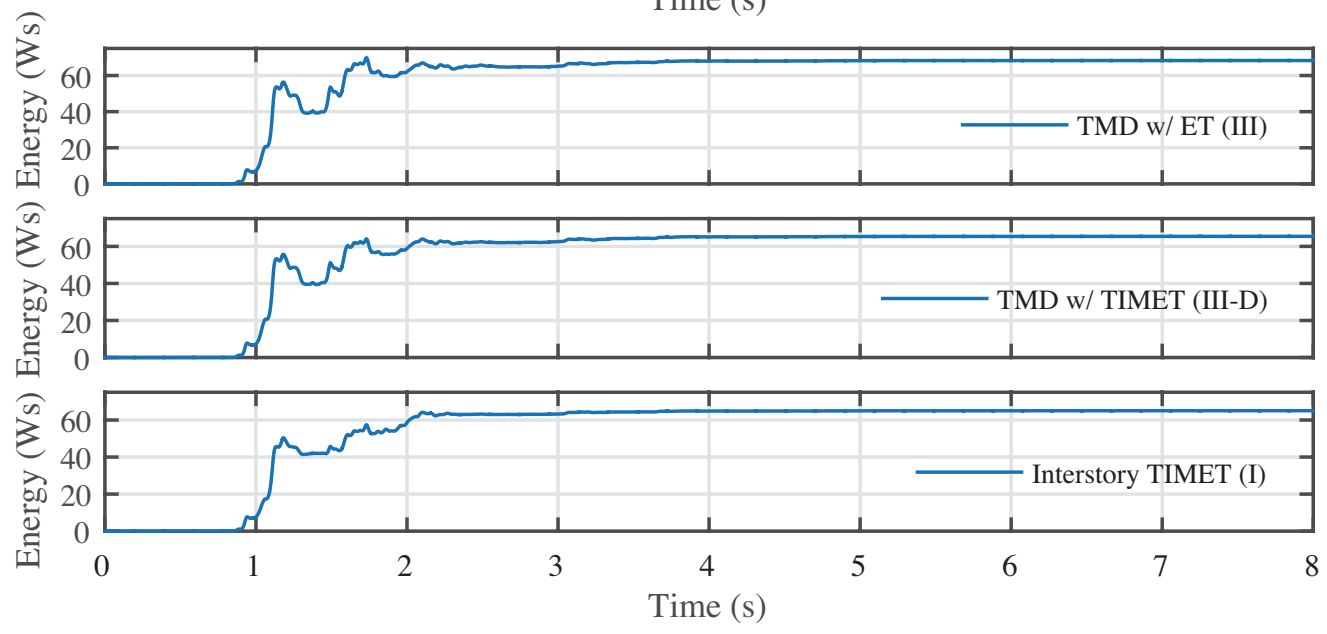

Figure 4. Time histories to JMA Kobe: (a) 3rd floor displacement, (b) Power generation, and (c) Input energy. 
(a)

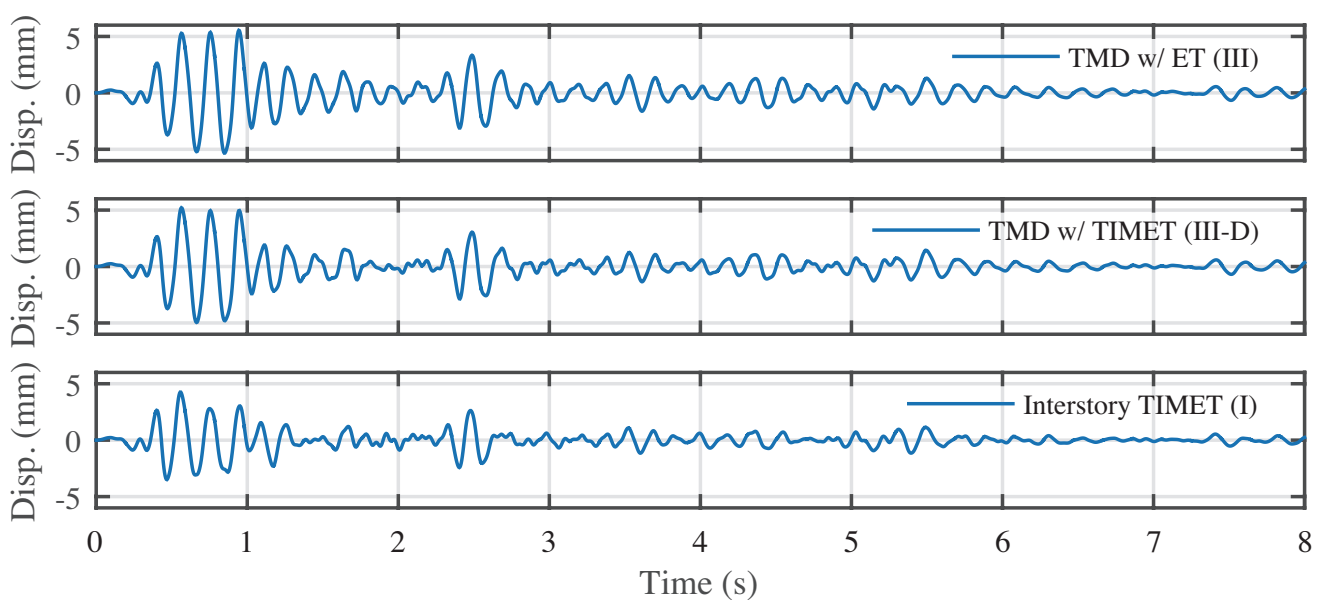

(b)

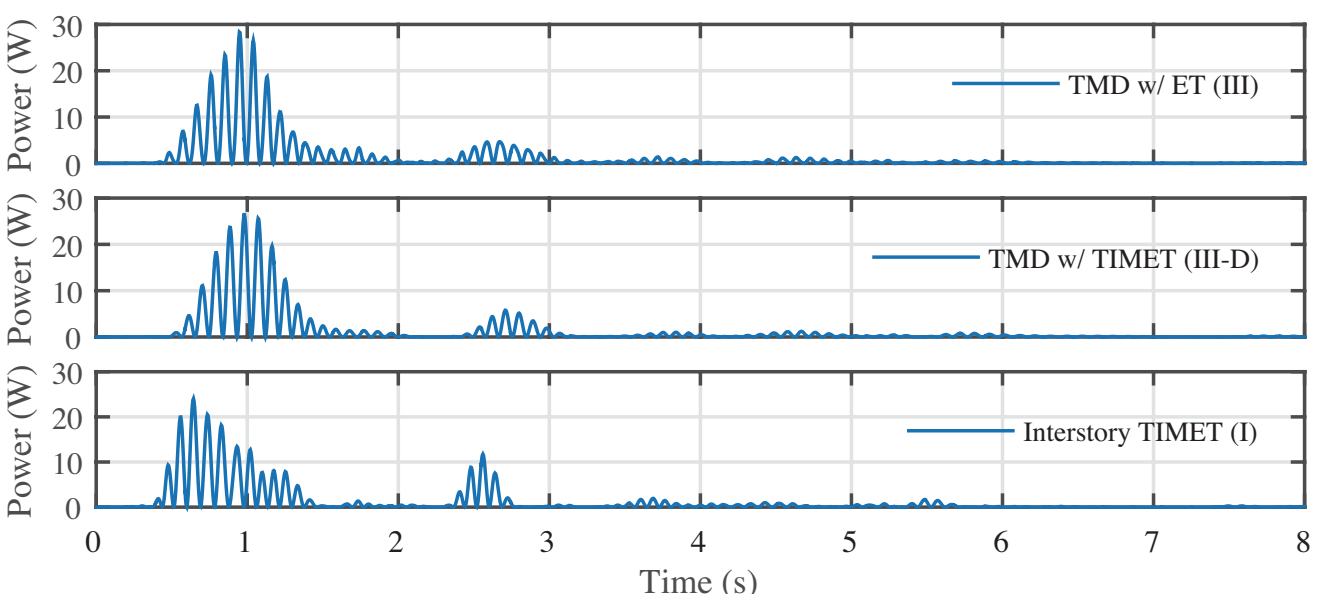

(c)

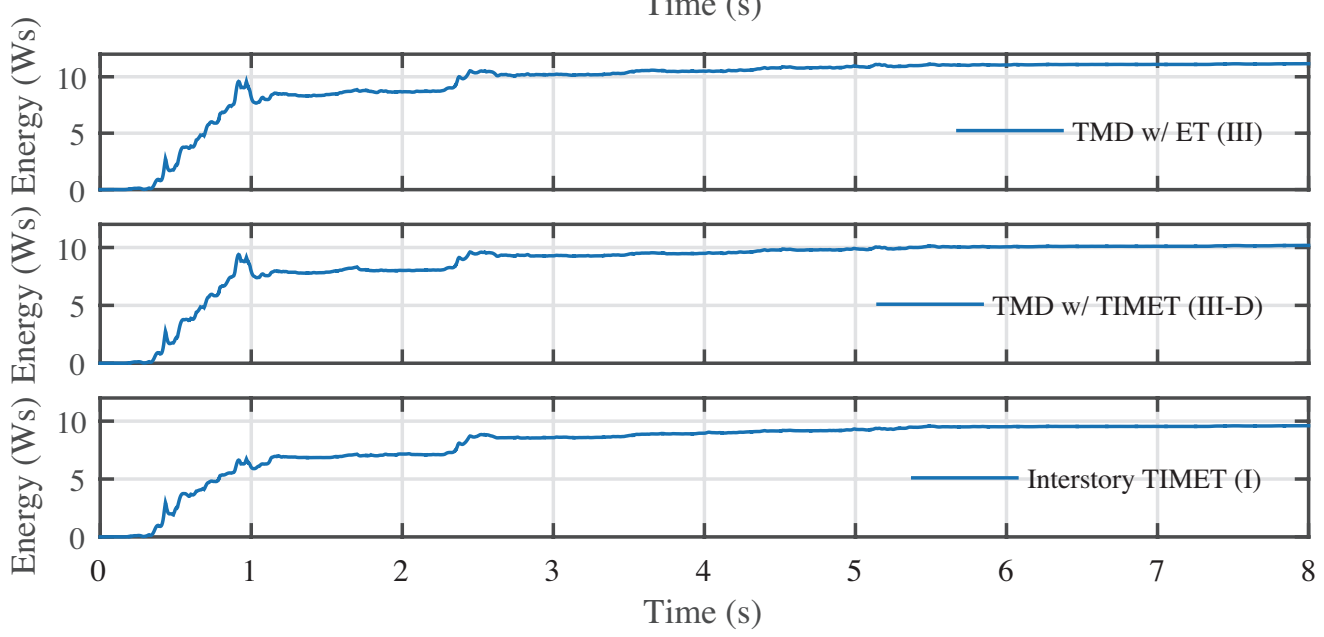

Figure 5. Time histories to El Centro: (a) 3rd floor displacement, (b) Power generation, and (c) Input energy. 
(a)

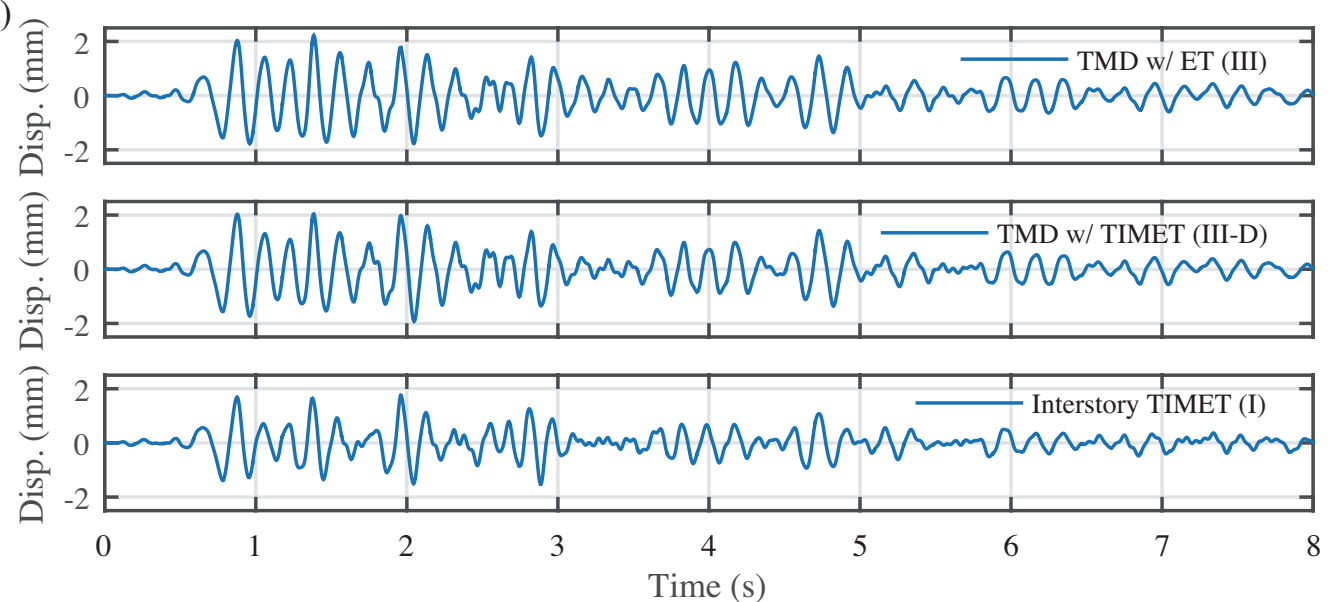

(b)
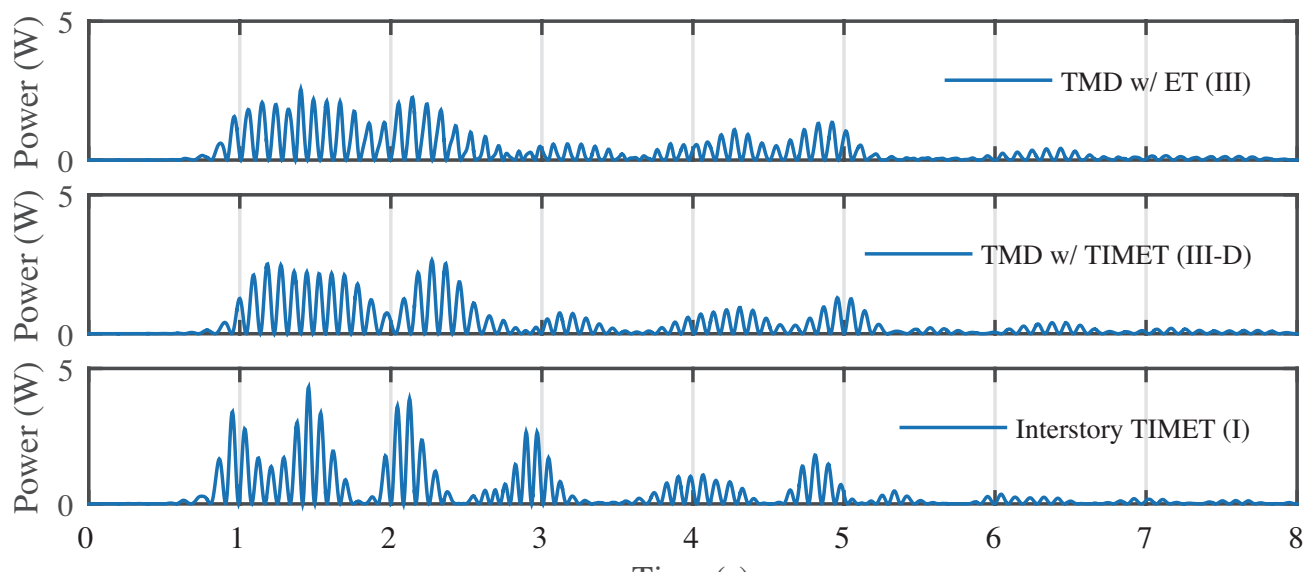

(c)

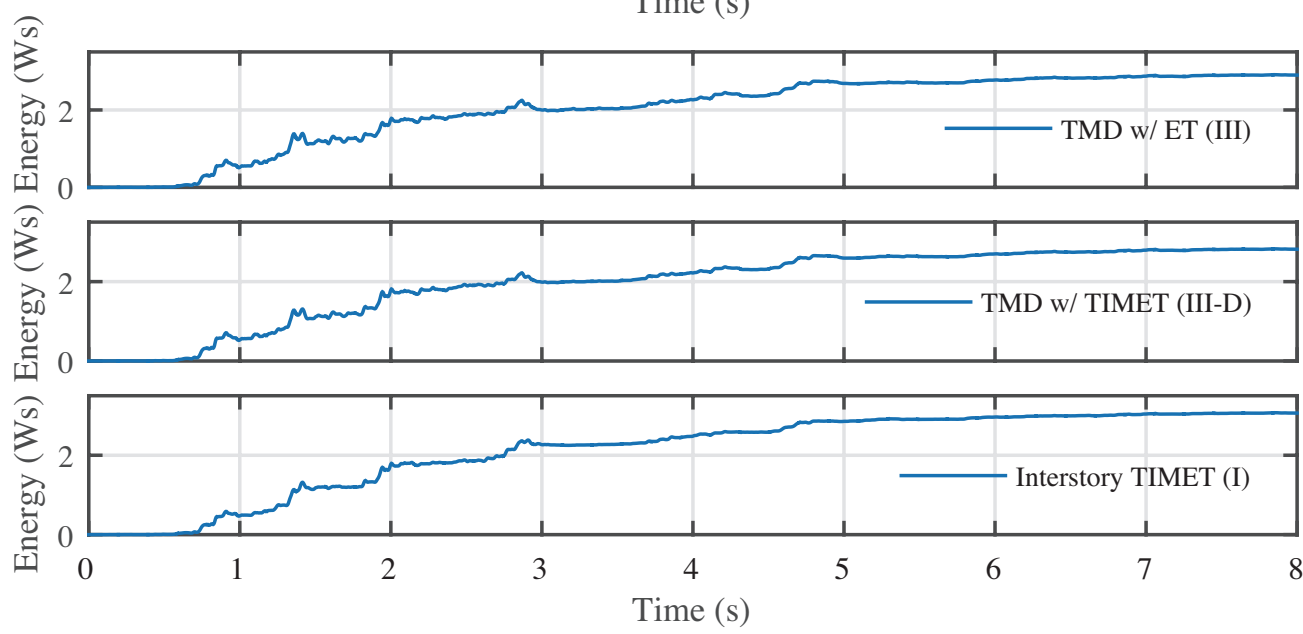

Figure 6. Time histories to Taft: (a) 3rd floor displacement, (b) Power generation, and (c) Input energy. 


\section{CONCLUSIONS}

\section{ACKNOWLEDGEMENT}

This research was supported by JSPS KAKENHI Grant number 26630256. The first author would also like to acknowledge support through the Grant-in-Aid for JSPS Fellows.

\section{REFERENCES}

1. Housner GW, Bergman L, Caughey T, Chassiakos A, Claus R, Masri S, Skelton R, Soong T, Spencer BF Jr, Yao J. Structural control: Past, present, and future. Journal of Engineering Mechanics 1997; 123(9):897-971.

2. Den Hartog JP. Mechanical Vibrations. Civil, Mechanical and Other Engineering Series, Dover Publications: New York, NY, 1985. URL https: / / books. google.co.jp/books? id=-Pu5YlgY4QsC.

3. Ikago K, Saito K, Inoue N. Seismic control of single-degree-of-freedom structure using tuned viscous mass damper. Earthquake Engineering \& Structural Dynamics 2012; 41(3):453-474, doi:10.1002/eqe.1138.

4. Lazar IF, Neild S, Wagg D. Using an inerter-based device for structural vibration suppression. Earthquake Engineering \& Structural Dynamics 2014; 43(8):1129-1147, doi:10.1002/eqe.2390. URL http://dx.doi.org/10.1002/ege.2390.

5. Krenk S, Høgsberg J. Tuned resonant mass or inerter-based absorbers: unified calibration with quasi-dynamic flexibility and inertia correction. Proceedings of the Royal Society of London A: Mathematical, Physical and Engineering Sciences 2016; 472(2185), doi:10.1098/rspa.2015.0718. URL http://rspa.royalsocietypublishing.org/content/472/2185/20150718.

6. Marian L, Giaralis A. Optimal design of a novel tuned mass-damper-inerter (TMDI) passive vibration control configuration for stochastically support-excited structural systems. Probabilistic Engineering Mechanics 2014; 38:156 - 164, doi:https://doi.org/10.1016/j.probengmech.2014.03.007. URL http://wWw.sciencedirect.com/science/article/pii/s0266892014000216.

7. Zhang SY, Jiang JZ, Neild S. Optimal configurations for a linear vibration suppression device in a multistorey building. Structural Control and Health Monitoring 2017; 24(3):n/a-n/a, doi:10.1002/stc.1887. URL http://dx.doi.org/10.1002/stc.1887.

8. Smith MC. Synthesis of mechanical networks: the inerter. IEEE Transactions on Automatic Control Oct 2002; 47(10):1648-1662, doi:10.1109/TAC.2002.803532. 


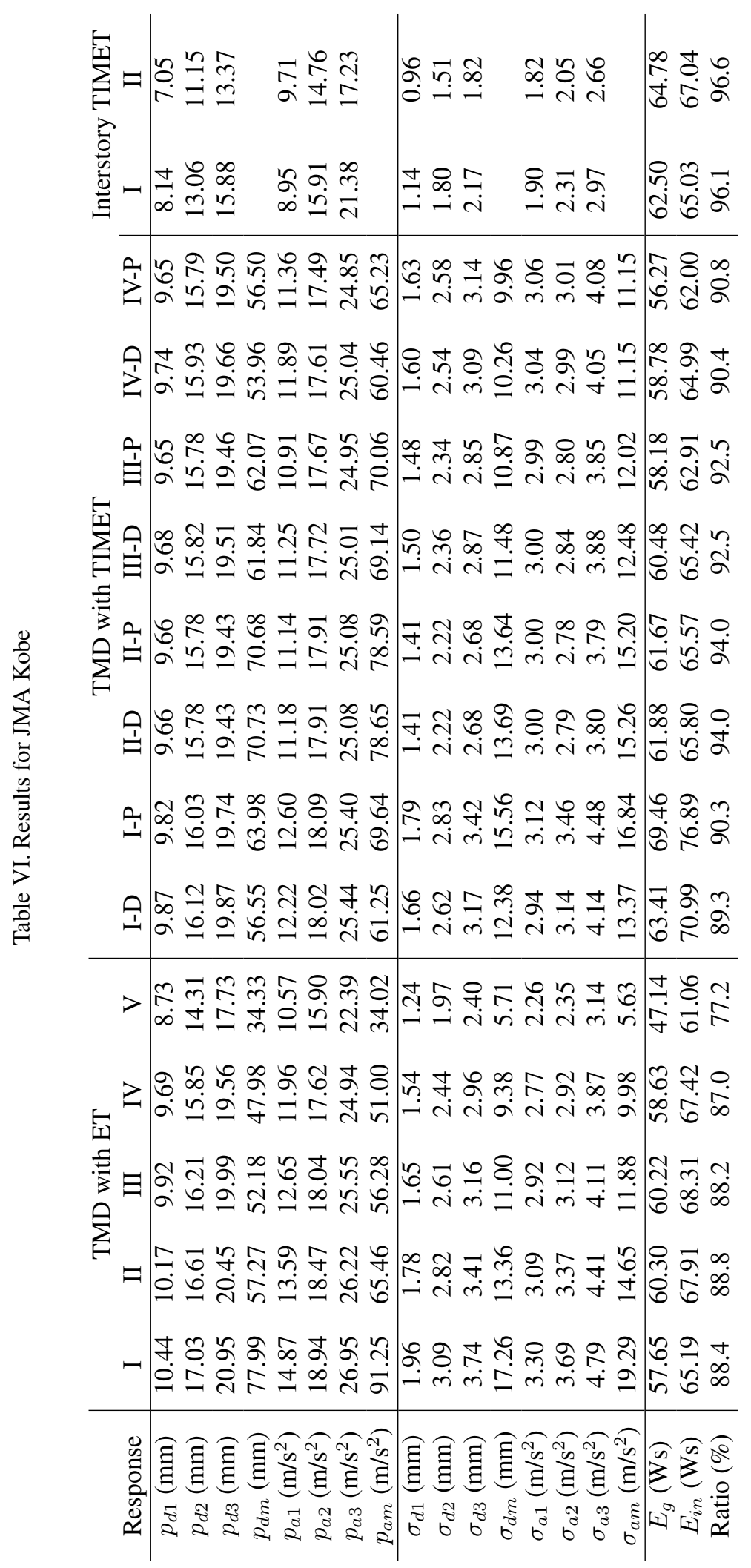




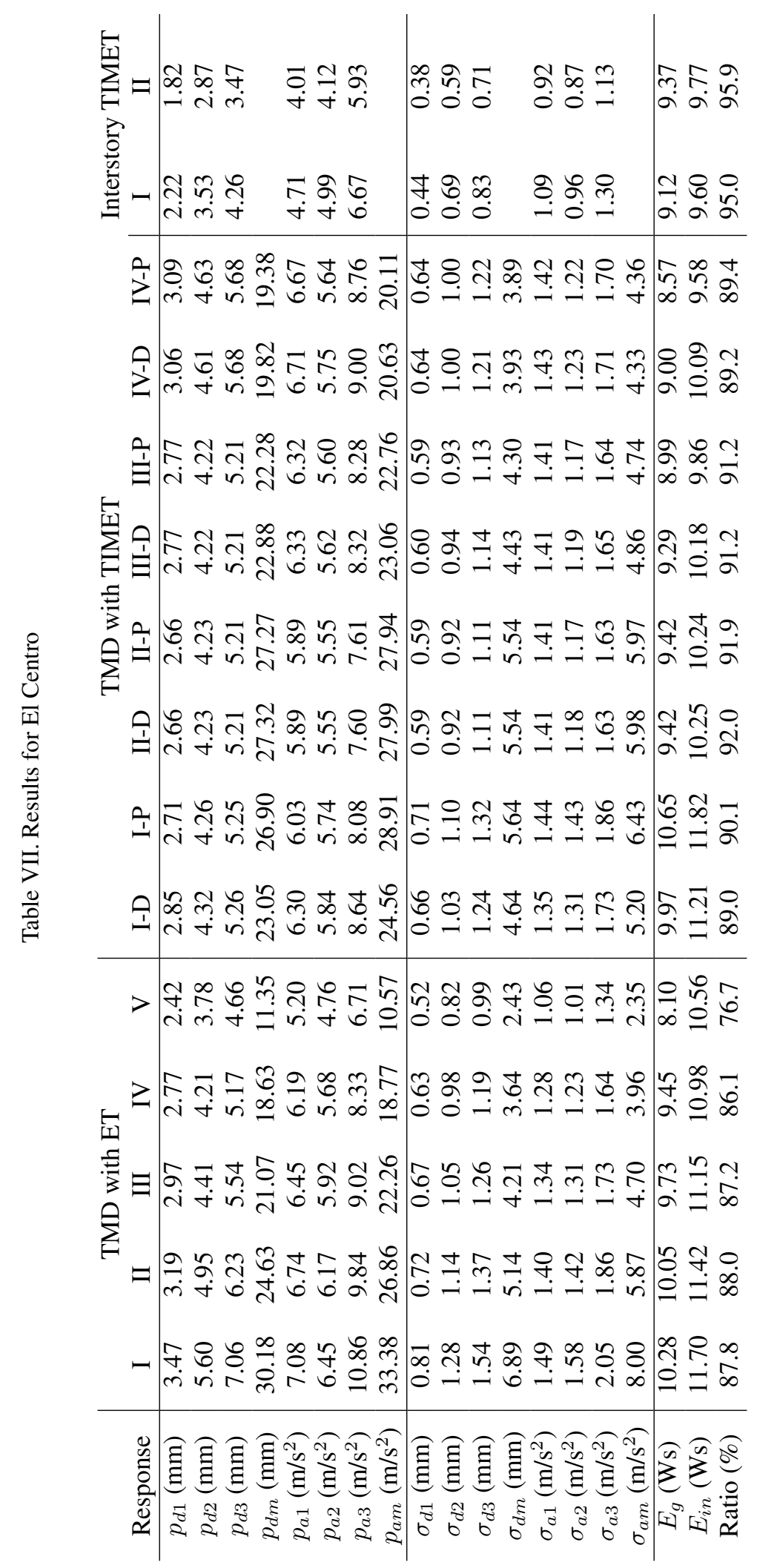




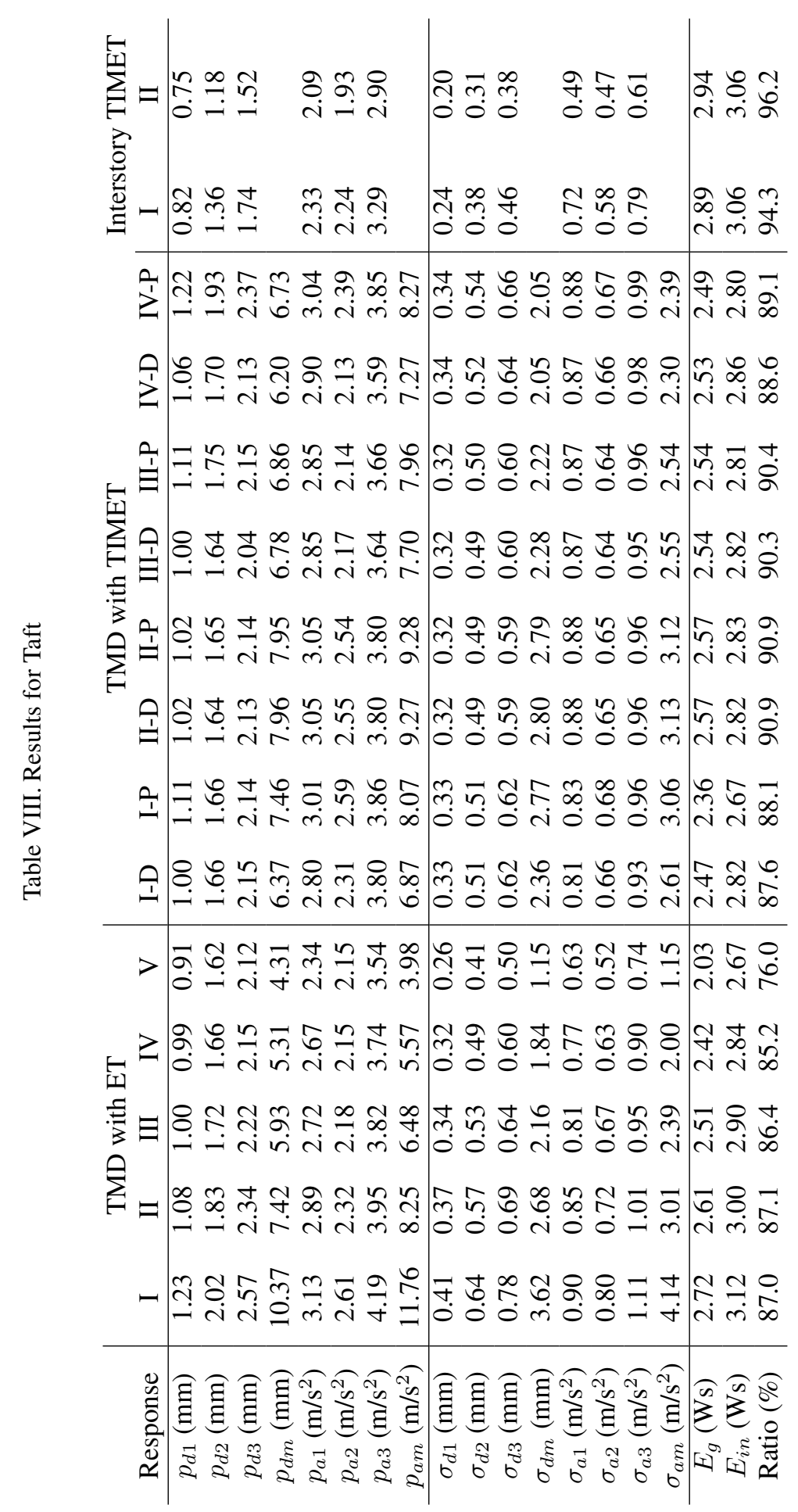


9. Wang FC, Hong MF, Lin TC. Designing and testing a hydraulic inerter. Proceedings of the Institution of Mechanical Engineers, Part C: Journal of Mechanical Engineering Science 2011; 225(1):66-72, doi:10.1243/ 09544062JMES2199.

10. Saitoh M. On the performance of gyro-mass devices for displacement mitigation in base isolation systems. Structural Control and Health Monitoring 2012; 19(2):246-259, doi:10.1002/stc.419. URL http://dx.doi.org/10.1002/stc.419.

11. Watanabe Y, Ikago K, Inoue N, Kida H, Nakaminami S, Tanaka H, Sugimura Y, Saito K. Full-scale dynamic tests and analytical verification of a force-restricted tuned viscous mass damper. Proceedings of the 15th World Conference on Earthquake Engineering, Lisbon, Portugal, 2012.

12. Ikago K, Sugimura Y, Saito K, Inoue N. Modal response characteristics of a multiple-degree-of-freedom structure incorporated with tuned viscous mass dampers. Journal of Asian Architecture and Building Engineering 2012; 11(2):375-382, doi:10.3130/jaabe.11.375.

13. Asai T, Ikago K, Araki Y. Outrigger tuned viscous mass damping system for high-rise buildings subject to earthquake loadings. 6AESE/11ANCRiSST Joint Conference, Urbana, IL, 2015.

14. Scruggs J, Iwan W. Structural control with regenerative force actuation networks. J. Struct. Contr. Health Monit. $2005 ; 12: 24-45$.

15. Cassidy I, Scruggs J, Behrens S, Gavin HP. Design and experimental characterization of an electromagnetic transducer for large-scale vibratory energy harvesting applications. Journal of Intelligent Material Systems and Structures 2011; doi:10.1177/1045389X11421824.

16. Asai T, Scruggs JT. Nonlinear stochastic control of self-powered variable-damping vibration control systems. 2016 American Control Conference (ACC), Boston, MA, 2016; 442-448, doi:10.1109/ACC.2016.7524954.

17. Asai T, Araki Y, Ikago K. Energy harvesting potential of tuned inertial mass electromagnetic transducers. Mechanical Systems and Signal Processing 2017; 84, Part A:659 - 672, doi:http://dx.doi.org/10.1016/j.ymssp.2016.07.048. URL http: //www.sciencedirect.com/science/article/pii/s0888327016302746.

18. Garrido H, Curadelli O, Ambrosini D. Improvement of tuned mass damper by using rotational inertia through tuned viscous mass damper. Engineering Structures 2013; 56:2149 - 2153, doi:http://dx.doi.org/10.1016/j.engstruct.2013. 08.044. URL http://www. sciencedirect.com/science/article/pii/S0141029613004112.

19. Cassidy IL, Scruggs JT. Nonlinear stochastic controllers for power-flow-constrained vibratory energy harvesters. Journal of Sound and Vibration 2013; 332(13):3134 - 3147.

20. Cassidy IL, Scruggs JT. Statistically linearized optimal control of an electromagnetic vibratory energy harvester. Smart Materials and Structures 2012; 21(8):085003. URL http://stacks.iop.org/0964-1726/21/i=8/a=085003.

21. Scruggs JT. Multi-objective optimization of regenerative damping systems in vibrating structures. 2007 American Control Conference, New York, NY, 2007; 2672-2677, doi:10.1109/ACC.2007.4282730.

22. Lin Y, Yong Y. Evolutionary kanai-tajimi earthquake models. Journal of engineering mechanics 1987; 113(8):11191137.

23. Dorato P, Abdallah C, Cerone V. Linear Quadratic Control: An Introduction. Krieger Publishing Company: Malabar, FL, 1995.

24. de Oliveira MC, Camino JF, Skelton RE. A convexifying algorithm for the design of structured linear controllers. Decision and Control, 2000. Proceedings of the 39th IEEE Conference on, vol. 3, 2000; 2781-2786, doi: 10.1109/CDC.2000.914229.

25. Shimomura T, Fujii T. Multiobjective control design via successive over-bounding of quadratic terms. Decision and Control, 2000. Proceedings of the 39th IEEE Conference on, vol. 3, 2000; 2763-2768, doi:10.1109/CDC.2000. 914226.

26. Warner EC, Scruggs JT. Control of vibratory networks with passive and regenerative systems. American Control Conference (ACC), 2015, Chicago, IL, 2015; 5502-5508, doi:10.1109/ACC.2015.7172200.

27. Dyke SJ, Jr BFS, Quast P. Role of control-structure interaction in protective system design. Journal of Engineering Mechanics Issue: object: doi:101061/jenmdt1995121issue-2, revision: rev:147926950844223046:doi:101061/jenmdt1995121issue-2, ; 121(2), doi:10.1061/(ASCE)0733-9399(1995)121:2(322).

28. Scruggs JT, Iwan WD. Structural control with regenerative force actuation networks. Structural Control and Health Monitoring 2005; 12(1):25-45, doi:10.1002/stc.50. URL http://dx. doi .org/10.1002/stc. 50.

29. Scruggs JT, Iwan WD. Optimal nonlocal and asymmetric structural damping using regenerative force actuation networks. Journal of Engineering Mechanics Issue: object: doi:101061/jenmdt2006132issue-9, revision: rev:1479273067672-25181:doi:101061/jenmdt2006132issue-9, ; 132(9), doi:10.1061/(ASCE)0733-9399(2006) 132:9(932).

30. Asai T, Spencer BF, Iemura H, Chang CM. Nature of seismic control force in acceleration feedback. Structural Control and Health Monitoring 2013; 20(5):789-803, doi:10.1002/stc.1496. URL http://dx.doi.org/10.1002/stc.1496.

31. Housner W, Jennings PC. Generation of artificial earthquakes. Journal of the Engineering Mechanics Division 1964; 90(1):113-150.

32. Spencer BF, Dyke SJ, Deoskar HS. Benchmark problems in structural control: part i-active mass driver system. Earthquake Engineering \& Structural Dynamics 1998; 27(11):1127-1139, doi:10.1002/(SICI) 1096-9845(1998110)27:11<1127::AID-EQE774〉3.0.CO;2-F.

33. Chopra A. Dynamics of Structures: Theory and Applications to Earthquake Engineering. Prentice Hall International Series in Civil Engineering And, Pearson/Prentice Hall: Upper Saddle River, NJ, 2007. URL https://books.google.co.jp/books?id=jce0QgAACAAJ. 